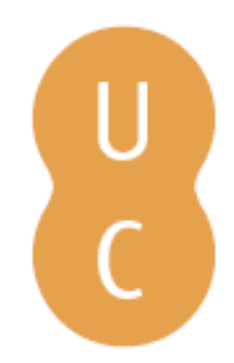

\title{
nommalina
}

Memória e contra-memória no cinema português: Quem és tu? de João Botelho

Autor(es): $\quad$ Torgal, Luís Reis

Publicado por: Imprensa da Universidade de Coimbra

URL

persistente: URI:http://hdl.handle.net/10316.2/38691

DOI: $\quad$ DOI:http://dx.doi.org/10.14195/978-989-26-1164-8_14

Accessed : $\quad$ 26-Apr-2023 14:51:05

A navegação consulta e descarregamento dos títulos inseridos nas Bibliotecas Digitais UC Digitalis, UC Pombalina e UC Impactum, pressupõem a aceitação plena e sem reservas dos Termos e Condições de Uso destas Bibliotecas Digitais, disponíveis em https://digitalis.uc.pt/pt-pt/termos.

Conforme exposto nos referidos Termos e Condições de Uso, o descarregamento de títulos de acesso restrito requer uma licença válida de autorização devendo o utilizador aceder ao(s) documento(s) a partir de um endereço de IP da instituição detentora da supramencionada licença.

Ao utilizador é apenas permitido o descarregamento para uso pessoal, pelo que o emprego do(s) título(s) descarregado(s) para outro fim, designadamente comercial, carece de autorização do respetivo autor ou editor da obra.

Na medida em que todas as obras da UC Digitalis se encontram protegidas pelo Código do Direito de Autor e Direitos Conexos e demais legislação aplicável, toda a cópia, parcial ou total, deste documento, nos casos em que é legalmente admitida, deverá conter ou fazer-se acompanhar por este aviso. 
Luís Reis Torgal

Universidade de Coimbra ${ }^{1}$

\section{MEMÓRIA E CONTRA-MEMÓRIA NO CINEMA PORTUGUÊS. QUEM ÉS TU? DE JOÃO BOTELHO}

Memória, criação e cinema

Toda a arte, toda a ciência, como todas as actividades da vida, supõem a existência da memória. Daí que se faça constantemente um apelo à "história", que é talvez a dimensão mais importante ou, pelo menos, mais comum de todo e qualquer discurso.

A memória implica um conhecimento da realidade e um desconhecimento, a tentativa de a apresentar como se de um retrato se tratasse ou a sua desconstrução e uma nova construção do objecto. Sublimadora e catártica, de forma consciente ou inconsciente, a memória supõe a recordação, o esquecimento e a "alteração" (a outra — alter — imagem). Parafraseando Nietszche, a Memória (a História) é tão necessária como desnecessária ao Presente e ao Futuro. Conforme escrevia o poeta brasileiro Carlos Drumond de Andrade: "Toda História é remorso". Na verdade, constantemente "remordemos" o "Passado", num acto de arrependimento, ou de lembrança feliz, ou de recordação que desejamos objectiva.

1 Professor Catedrático Aposentado de História da Faculdade de Letras da Universidade de Coimbra, Coordenador de investigação do grupo de pesquisa "Arquivo da Memória e História do Século xx", Centro de Estudos Interdisciplinares do Século xx da Universidade de Coimbra (CEIS20).

2 Este texto, inédito, que considerámos oportuno para um volume de uma garrettiana, a Doutora Ofélia Paiva Monteiro, foi a base de uma comunicação proferida em de 9 fevereiro de 2002, no colóquio realizado na Cinémathèque de la Ville Luxembourg, a propósito da retrospectiva da obra cinematográfica de João Botelho, organizada pelo Centro de Documentação sobre Portugal da Universidade de Trier (Alemanha) e pelo Instituto Camões do Luxemburgo. Apenas o revimos e actualizámos. 
O cinema, como a história, também vai "remordendo", e "remoendo", os elementos que tem na memória. Alguém dizia, por altura do centenário do cinema (1995), que andamos há cem anos a contar as mesmas "estórias", embora de maneira diferente e, naturalmente, com qualidade diferente.

Neste sentido, o realizador, integrado no Presente, ou no "Presente" que ele próprio escolhe e sente, analisa um tema em função desse seu espaço. Mas não se trata geralmente - ressalvando talvez aquele que se integra na arte engagée (por mais interessante que seja a ideologia a que se prenda) ou o que deseja fazer um simples produto de mercado, consoante os estudos de marketing, e por melhor que seja esse produto - de uma relação mecânica. Normalmente ele insere-se nesse Presente para o desmontar e criar "outro Presente". E também olha o Passado com esse mesmo olhar e com essa mesma vontade de o ultrapassar. O Passado nem sempre é o Passado comummente tido como "Passado Histórico". Por vezes é o Passado do próprio cinema já produzido. Daí que o espectador tenha muitas vezes a sensação do "já visto", dejà vu, na expressão francesa de maior significado expressivo.

Por isso, no cinema, em certos casos, em vez de se inventar uma "estória", em toda a sua concepção (o "novo cinema" português é geralmente um "cinema de autor", o que não significa que até os seus filmes não estejam impregnados de história do cinema português ou... francês), utiliza-se a história ou a literatura, que pode ser entendida como um objecto criativo com "história", ou seja, produzido numa dada época e que por vezes se torna "clássica” ou entendida como "modelo formal". O remake é a forma mais paradigmática de voltar a um mesmo tema, para o "remorder", reconstruindo-o, ou até para o contrariar ou "criticar". Há no cinema, portanto, uma memória e uma "contra-memória". A mudança de modelos estéticos e de tipo de argumentos está sujeita às "leis da história", consideradas não como "regulamentos", que traçam necessariamente um caminho, mas como tendências que vão surgindo, de forma consciente ou inconsciente. Assim, o "novo" no cinema surpreende pelo facto de contrariar a "lei", o "costume", e é assim que se impõe, pelo menos momentaneamente, como um espaço de criação "nunca alcançado". Daí a força do "cinema novo", ou "novo cinema", nos anos sessenta e setenta do século xx português. Ele teve a força de uma militância, que impôs um objecto de arte, de "qualidade" ou de "outra qualidade". Daí a força hoje de alguns cineastas pela sua capacidade 
de surpreender, sejam eles o velho e sempre novo Manoel de Oliveira, João César Monteiro e o seu estranho mundo (quase filmou a sua morte) ou... João Botelho, pela sua variedade temática e pela forma sempre diferente e original de a tratar.

\section{Literatura e cinema}

Falemos da literatura e da sua adaptação ao cinema.

No Estado Novo, António Ferro nunca deixou de insistir na importância desse cinema feito com argumentos não criados com objectivos comerciais, mas imaginado a partir de obras já consagradas 3 . E o "cinema literário" realizado em pleno Estado Novo não tem surpresas. Ele resulta afinal de representações de uma literatura que se conjugava com realidades culturais e sócio-políticas do Presente vivido ou que se desejava apresentar como modelo ${ }^{4}$.

Ainda o Estado Novo não estava criado, embora estivesse em processo de formação, e surgiu o primeiro filme português sonoro, A Severa (1931), de Leitão de Barros, baseado na obra homónima de Júlio Dantas. Trata-se de uma obra de literatura histórica muito popular, sobre a vida da fadista do século xix conhecida por Severa, razão por que foi adaptada ao cinema, por um realizador que se há-de tornar um dos mais significativos do Estado Novo. Algo de semelhante se passará em 1938, com a adaptação ao cinema por Chianca de Garcia, neste caso um realizador de ideologia não salazarista, da obra de literatura ultra-romântica, de certo cunho social, Rosa do Adro, da autoria do escritor Manuel Maria Rodrigues - trata-se, com efeito, de um romance muito popular, capaz de interessar um vasto público. Algo de idêntico ainda sucedeu, em 1943, com o clássico (e muito divulgado) romance de Camilo Castelo Branco, Amor de Perdição, adaptado por António Lopes Ribeiro, o realizador mais bem identificado com o regime de Salazar. Mas, para além de razões de popularidade das obras literárias, também será passível de outra interpretação a adaptação dos livros de Júlio

3 António Ferro, Teatro e Cinema. 1936-1949, Lisboa, Edições SNI, 1950. Veja-se o seu discurso de 30 de dezembro de 1947, proferido na festa de distribuição dos Prémios de Cinema, em que classificou tipologicamente o cinema português - p. 61 ss..

4 Ver o nosso artigo "Cinema, estética e ideologia no Estado Novo", in Estudos do Século xx, n. ${ }^{\circ}$ 1, "Estéticas do Século", Coimbra, Quarteto - CEIS20, 2001. 
Dinis, que constituem a "trilogia da aldeia", ou seja, As Pupilas do Senhor Reitor, Os Fidalgos da Casa Mourisca e A Morgadinha dos Canaviais. Eram romances campestres, onde surgem, num ou noutro caso com mais acentuação, mas em todos a defesa do ruralismo contra os vícios da cidade, as ideias de conciliação de classes, de elogio do trabalho honesto, de crítica à burguesia liberal e à nobreza ociosa, valores ético-políticos que estavam de acordo com a ideologia do tempo. Foram, na verdade, todos adaptados ao cinema: respectivamente, em 1936 por Leitão de Barros, em 1938 por Arthur Duarte e em 1949 pelo italiano Caetano Bonucci. O primeiro e talvez o mais popular, As Pupilas do Senhor Reitor, teve ainda um remake em 1960 por Perdigão Queiroga.

Independentemente de outros exemplos que poderiam ser acrescentados - um dos quais será exactamente a peça histórica de Almeida Garrett, Frei Luís de Sousa, adaptada ao cinema por António Lopes Ribeiro em 1950, e que recebeu o Grande Prémio do Secretariado Nacional de Informação (SNI), herdeiro, em 1944, do Secretariado de Propaganda Nacional (SPN), criado em 1933 - , poderemos notar que, a partir dos anos cinquenta do século passado, quando o salazarismo começa a entrar em crise e, todavia, começa a permitir uma relativa "abertura", embora sempre controlada, surge a adaptação ao cinema de uma literatura de sentido diferente, como uma espécie de contra-memória literário-cinematográfica. Trata-se da literatura neo-realista, que inicia o seu ciclo com a adaptação do livro de Leão Penedo O Circo, na obra cinematográfica de Manuel Guimarães, Saltimbancos (1951). A partir daí vários autores neo-realistas, de formação marxista e católico-social, foram adaptados ao cinema, tais como Bernardo Santareno, Carlos de Oliveira e, sobretudo, Fernando Namora.

Apesar de se dizer, por vezes, embora discorde dessa asserção, que o "cinema novo" português começou com Dom Roberto (1962), de Ernesto de Sousa, que tem por base, uma vez mais, um argumento do citado escritor neo-realista algarvio Leão Penedo, o certo é que ele se inicia com Os Verdes Anos (1963), de Paulo Rocha. Surge então, como se dizia, o "cinema de autor", que virá a ter um certo prestígio no estrangeiro e uma certa fama nos meios intelectuais portugueses de "esquerda", não deixando também de seduzir, por contraditório que pareça, os próprios meios oficiais de um Estado cada vez mais em crise de identificação e de identificação da sua cultura. Mas, será que este "cinema novo", ou "novo 
cinema" (como pretende Paulo Filipe Monteiro5), não se integrará também numa memória ou numa contra-memória?

Em primeiro lugar, a influência francesa, da Nouvelle Vague e dos Cahiers du Cinéma, é uma evidência já por de mais notada. Porém, que me perdoe Paulo Rocha se digo uma tremenda incorrecção, sempre vi em Os Verdes Anos sombras de contra-memória de Maria Papoila (1937), a popular tragicomédia popular de Leitão de Barros. Uma das figuras centrais de Os Verdes Anos é também uma "criada de servir" ou uma "empregada doméstica" (como já se dizia no tempo), só que, no caso de Maria Papoila, ela surge como a grande heroína do filme, que tem um final feliz (termina como noiva de um "filho de família”, tendo ultrapassado os perigos da capital, apesar do seu inicial analfabetismo e da sua ingenuidade, mas mercê dos seus valores éticos tradicionais), enquanto, em Os Verdes Anos, Ilda é assassinada na cena final pelo namorado (Júlio), que se sente atordoado pela pressão social da cidade, que acaba por acusá-lo.

Passando da literatura para a história literária, aligeirada por valores românticos e até musicais, pode dizer-se que no Estado Novo se sente uma certa adaptação às circunstâncias. A "trilogia" histórico-literária de Leitão de Barros começa com Bocage, em 1936, num filme musicado, sem grandes preocupações de verdade histórica, mas com a intenção de enquadrar o poeta nos seus dramas amorosos e afastá-lo do "Bocage das anedotas". Camões, de 1946, é, sobretudo, o Camões lírico, também dos amores infelizes ("Erros meus, má fortuna, amor ardente" - o verso de Camões é também o subtítulo do filme), ainda que não deixe de ter nele grande significado o Camões épico. O filme, que surge logo a seguir à Segunda Grande Guerra, parece fazer sobressair a ideia do regresso ao passado nacionalista redentor. O erguer das bandeiras com as datas de alguns dos "grandes acontecimentos nacionais" que se seguem a Alcácer Quibir (1640 - Restauração, 1810 - vitória sobre as tropas francesas invasoras, 1895 - as heróicas campanhas africanas, e 1940 - duplo centenário da Fundação e da Restauração da Nacionalidade) se, segundo uma memória tradicionalista, se adaptava ao espírito

5 "Uma margem no centro: a arte e o poder do "novo cinema", in Luís Reis Torgal (coordenador), O cinema sob o olhar de Salazar, Lisboa, Temas e Debates / Círculo de Leitores, 2011 (3. ${ }^{a}$ edição), p. 306 ss.. 
monárquico, paralelo ao regime (mesmo fora dele), de Afonso Lopes Vieira, que inspirou o roteiro e a quem a obra foi dedicada postumamente, também se coadunava com a ideologia "historicista e "refundacionista" do regime de Salazar. Vendaval Maravilhoso (1949), a saga luso-brasileira sobre a vida também amorosa e poética do anti-esclavagista Castro Alves, já parece identificar um novo espírito, construído em momento de afirmação de "nova identidade" do país, onde se quer afirmar os valores humanistas e universais, mais do que os valores de um nacionalismo estrito.

Mas, a "superprodução" (na relatividade do cinema português), de Jorge Brum do Canto, Chaimite (1953), sobre as campanhas em Moçambique de Mouzinho de Albuquerque, Paiva Couceiro, Caldas Xavier e outros "heróis", já reafirma de novo o nacionalismo e até um sentimento colonial de tipo épico que não se identificava exactamente com a lógica assimilacionista africana que começava a despontar em Portugal, com a legislação dos anos cinquenta e como resposta ao anticolonialismo que vai crescer de peso e influência nesse decénio, para se manifestar com toda a força nos anos sessenta. E, todavia, apesar da sua maneira de interpretar a "história" não ser estruturalmente diferente do filme de propaganda de António Lopes Ribeiro, Feitiço do Império (1940), realizado em plena Segunda Guerra, que é até mais revelador do que se considerava o sentido "humanista" e respeitador das "tradições indígenas" do nosso colonialismo, Chaimite foi dos filmes mais vistos do cinema português e mais promovido pelo regime de Salazar-Caetano e pelas suas "forças morais", nomeadamente a Mocidade Portuguesa e os meios militares ${ }^{6}$.

Não é um filme histórico o outro filme de propaganda e de ficção de António Lopes Ribeiro, Revolução de Maio (1937), pois não se trata, como o nome parece indicar, de um filme sobre a dita "Revolução Nacional" de 28 de maio de 1926, que abriu as portas ao Estado Novo (formalmente fundado em 1932-1933). Mas, tem atrás de si uma "visão da história", a "história" do Estado Novo, precisamente indiciada com essa "Revolução", e cujo primeiro decénio fora celebrado em Maio de 1936 ("X Ano da Revolução Nacional"). Na verdade, pretende-se valorizar a

6 Ver Jorge Humberto Seabra, Cinema, Império e Memória no Estado Novo. O caso "Chaimite" de Jorge Brum do Canto, Tese de mestrado. Coimbra, Faculdade de Letras da Universidade de Coimbra. 1993, e África Nossa. O império colonial na ficção cinematográfica portuguesa. 1945-1974, Coimbra, Imprensa da Universidade, 2011. 
"história do espírito revolucionário de Maio" - interpretado como um tempo de primavera, de azul florido, de Paz e de Progresso - por oposição a "outra revolução" que não se fizera em Portugal graças a Salazar, uma "revolução vermelha", feita de violência, como sucedera durante a Primeira República e se procurara reproduzir em Fevereiro de 1927 contra a Ditadura Nacional saída da "Revolução de Maio".

Depois do 25 de Abril de 1974, a chamada (especialmente fora de Portugal) "revolução dos cravos", o registo cinematográfico em relação à história é, sobretudo, o da contra-memória. Assim sucede, logo nesse ano de 1974, com Brandos Costumes de Alberto Seixas Santos, que é uma anti-memória da Revolução de Maio e de toda a história do Estado Novo, a terminar na "Guerra Colonial".

Non ou a Vã Glória de Mandar (1990), de Manoel de Oliveira - "História de Portugal" contada pela voz de um alferes na Guerra Colonial de Angola - é afinal a memória da "outra história", aparecendo como uma espécie de "refundação" de "outra ideologia histórica". Por sua vez, o interessante filme Aqui del Rei (1991), de António Pedro Vasconcelos, é uma espécie de "anti-Chaimite", de "outra visão" dos acontecimentos ultramarinos e continentais do final do século xix e de outra visão diferente do cinema, tomando como referência o filme de Jorge Brum do Canto.

Há, porém, nos anos recentes, uma tentativa de utilizar a linguagem do cinema para "narrar rigorosamente a história". Assim sucede com O Processo do Rei (1989), de João Mário Grilo. Trata-se do processo do nosso rei D. Afonso VI promovido pelo seu irmão D. Pedro e por um grupo de aristocratas, em nome dos "interesses políticos nacionais". Grilo teve com certeza na memória um filme histórico, não da queda de um rei mas da sua ascensão ao Poder, um rei francês, ocorrida sensivelmente pelo mesmo tempo e contada pelo genial Roberto Rosselini, La Prise du Pouvoir par Louis XIV (1966). De idêntica maneira, embora numa perspectiva diferente, pretende ser um dos filmes de Oliveira, Palavra e Utopia (2000), em que se procura fazer a análise histórica, quase só do discurso, do Padre António Vieira. 
João Botelho e a nova versão cinematográfica de Frei Luís de Sousa

Qual o papel de João Botelho no contexto desta reflexão sobre a memória e a contra-memória?

A sua cinematografia é variada e é reveladora de uma vontade de inovar e de surpreender, colocando-se tanto na linha analítica de textos e de vidas (Conversa Acabada, 1981, sobre a correspondência entre Fernando Pessoa e Mário de Sá-Carneiro, terminada com o suicídio deste em Paris) ${ }^{7}$, como na "actualização" social de um obra clássica (Tempos Difíceis - Este tempo, 1988, com base na obra de Charles Dickens, Hard Times, for These Times), como a comédia de costumes de crítica à sociedade portuguesa (Tráfico, 1988)... Um dos seus primeiros filmes, Um Adeus Português (1985), é também uma das primeiras películas a abordar a memória dramática da Guerra Colonial. Não é uma abordagem directa da guerra, como praticamente nenhuma outra em filmes portugueses (nem Non de Oliveira, nem a obra de Joaquim Leitão, Inferno, 1999, que, a meu ver, se trata de um filme sem grande profundidade e de mais uma ocasião perdida para pensar o drama das nossas jovens gerações dos anos sessenta e setenta ${ }^{8}$ ), mas de uma reflexão sobre o tédio, a doença, ou a morte, ou a "mortinha", da nossa sociedade em crise de fim do regime.

Quem és tu? é, pois, um regresso ao tema da tragédia de Almeida Garrett. Poucas vezes terá sucedido este regresso a um tema já abordado no cinema português (se pusermos entre parênteses o cinema mudo, que iniciou a experiência de passar para o ecrã algumas das obras literárias "clássicas" que depois reapareceram em fonofilmes). Sucedeu, no domínio da literatura com Amor de Perdição (1978), por Manoel de Oliveira, que, apesar de se interessar pelo Romantismo, tem sobretudo em Agustina Bessa Luís a musa inspiradora dos seus argumentos. Na nova versão, bem diferente da citada adaptação de 1943, de António Lopes Ribeiro, surge em Oliveira a costumada forma analítica, e um pouco irónica, de abordar a tragédia ultra-romântica. Inês de Portugal (1997), de José Carlos Oliveira, é também um remake ou uma tentativa de tratar o tema

\footnotetext{
7 Nesta linha, João Botelho adaptou recentemente ao cinema o Livro do desasossego, de Bernardo Soares (Fernando Pessoa).

8 Mais recentemente (2006), Joaquim Leitão apresentou o filme 2013 Purgatório, cujo cenário se desenvolve no próprio ambiente da guerra. Mas o filme acaba por ser pouco mais do que um thriller, sem grande consistência.
} 
trágico e romântico português, e universal, do século xıv, de uma forma social, diferente da maneira esteticista e "iberista" (de resto, tratou-se de uma produção luso-espanhola) do tratamento de Leitão de Barros, em Inês de Castro (1945).

Não se pretende comparar os dois filmes que tiveram por base a peça com que - no dizer dos críticos literários — se abre o teatro moderno português, Frei Luís de Sousa (1843-1844). Trata-se de filmes produzidos em datas muito distintas:

Frei Luís de Sousa surge em 1950, altura em que todos os estudantes a partir do $2 .^{\circ}$ ciclo dos liceus (hoje dir-se-ia o $3 .^{\circ}$ ciclo do ensino básico) conheciam ou eram obrigados a conhecer a obra de Garrett e num tempo em que o regime salazarista procurava, no pós-guerra, reforçar a memória das grandes figuras históricas de referência, por exemplo Camões ou D. Sebastião, vendo neste jovem rei não tanto o "vencido de Alcácer Quibir", mas a figura central do "sebastianismo", feito de promessas de "redenção da Pátria" (ver Camões, de Leitão de Barros), mesmo com sacrifício pessoal. Quem és tu? aparece ao público em 2000, um ano depois do centenário do nascimento do escritor (1799-1999), num tempo em que já a sua obra teatral, considerada geralmente como "obra-prima", era em muitos casos esquecida, em especial entre os jovens estudantes, talvez porque o Estado não entendesse dever salientar uma memória histórico-literária considerada de "menor significado" depois do 25 de Abril (recorde-se como foi lateralizado o estudo escolar de Os Lusíadas de Camões).

São, por outro lado, obras de realizadores muito diferentes. António Lopes Ribeiro é uma espécie de "monstro sagrado" do cinema da época salazarista. João Botelho, que teve a sua formação de base nos conturbados anos sessenta, representa não já o "cinema novo", mas o cinema mais criativo do pós-25 de Abril, sem os traumas da anti-memória de 1974 e anos imediatos.

Mas, seja como for, é quase obrigatório um exercício de confronto meramente referencial:

Saliente-se que ambas as obras abrem com textos cinematográficos que não pertencem ao início da obra de Almeida Garrett e que marcam, por si só, uma diferença significativa entre eles. O filme de Lopes Ribeiro começa com uma curta cena do início do Acto II da peça, em que Telmo, o aio de D. João de Portugal, presumivelmente morto em Alcácer Quibir, recorda Camões e o seu livro imortal, critica os ricos que abandonaram o Poeta no fim da sua vida e afirma, como predizendo a tragédia, numa visão ética católica: "O céu fez-se para os 
bons e os infelizes". Assim se abre caminho ao início do Acto I da peça, com que continua o filme, no qual D. Madalena de Vilhena, "viúva" de D. João e agora casada com Manuel de Sousa Coutinho, lê em Os Lusíadas o passo referente a Inês de Castro: "Naquele engano de alma ledo e cego/ que a fortuna não deixa durar muito." A cena do princípio de Quem és tu? é inteiramente nova: é uma espécie de "ante-acto", bastante longo (dura cerca de 20 minutos) a que o próprio realizador chamou: "Sonhos e pesadelos sebastianistas de Maria de Noronha, filha de Madalena de Vilhena e de Manuel de Sousa Coutinho".

Nos sonhos de Maria, com que se procura integrar a peça, entre imagens trágicas e macabras, D. Sebastião, na voz do narrador, vai falando das profecias do Bandarra e de Camões, da sua infância, como ficou órfão de pai, como foi abandonado pela mãe, D. Joana de Áustria, como foi criado pela avó, D. Catarina, no seio da corte decadente do avô, D. João III, com halos da Santa Inquisição, e como foi educado pelo tio-avô, Cardeal D. Henrique. Fala o jovem e sacrificado rei, que começou a reinar aos 14 anos, nas suas doenças, no seu voto de castidade, nos sonhos do "Quinto Império", na loucura da campanha de África e na ideia de "Cruzada", no insulto que dirigiu a conselheiros assisados que o desencorajaram de a levar a cabo, do exército miserável quanto aparatoso que organizou... E Maria vê a trágica batalha de Alcácer Quibir, em que o rei, desaparecendo nas brumas, exclamou "Morrer sim, mas de vagar... O Céu...". D. Sebastião volta a falar, depois da batalha, para dizer: "Desaparecido durante séculos, vivi na alma do povo português". Sebastião era, pois, nos sonhos tísicos de Maria, ao invés da política prática de Filipe II para com Portugal, comprando aos mouros os nobres prisioneiros da batalha, o "Cristo português", o "Redentor das almas", o "Rei Encoberto".

De algum modo, nesta abertura, cujos traços largos captámos do próprio visionamento do filme, consciente ou inconscientemente João Botelho fez jus à interpretação de uma estudiosa do teatro português, a italiana Luciana Stegagno Picchio, que considerava que Garrett, quase contraditoriamente, quis nesta peça exorcizar o sebastianismo?.

O resto do filme de Botelho é a própria peça de Garrett - a qual, no seu testemunho, quis fazer de novo recordar (talvez sem grande resultado, tendo

9 Storia del teatro portoghese, Roma, Edizioni dell'Ateneo, 1964, pp. 186-188. 
em conta a sua distribuição, o que também não deixa de ser sintomático dos mecanismos comerciais do cinema e da falta de interesse oficial em "divulgar" a "leitura" das grandes obras literárias ${ }^{10}$ ) — que ele segue rigorosamente, como se se tratasse de uma encenação teatral que, significativamente, se inicia com o abrir da cortina do palco e termina com ela a fechar-se.

No entanto, uma encenação, por mais que se respeite o texto, é sempre a visão do encenador ou, neste caso, do realizador de cinema. Do ponto de vista estético, há na obra um certo tom barroco e até rembrandtiano, e surge um acentuado sentido anticlerical nas imagens finais, invertendo a eventual interpretação cinematográfica - apesar de tudo, mais cinematográfica — de António Lopes Ribeiro, que se deixa seduzir pela ideia de sacrifício e de santidade cristã ao olhar a morte de Maria e ao apreciar a entrada para o convento domínico de Manuel de Sousa Coutinho (Frei Luís de Sousa) e de Madalena, causada pelo surgir anunciado (nas profecias de Maria e do aio Telmo, espécie de coro do teatro grego) de D. João de Portugal, na figura do Romeiro. A caracterização das figuras do clero e o seu modo de falar, longe de justificar o sacrifício redentor, conduz a sensibilidade do espectador ao repúdio das fórmulas morais impostas não pela religião, mas pelo clero. Talvez afinal tenha sido esta a interpretação do próprio autor da peça, integrado que estava no mundo liberal.

E o título da obra de João Botelho? - Quem és tu? Que significado terá na lógica e na sensibilidade que o realizador pretende transmitir?

Note-se que já um estudioso de Garrett, António Salgado Júnior, havia escrito, como uma "Fantasia crítica à maneira de acto dramático", um texto de ficção em que Garrett se interrogava sobre o sentido da construção da sua peça e em que punha em paralelo a "verdade poética" e a "verdade histórica". O texto chamava-se Romeiro, Romeiro! Quem és tu? (1956) ${ }^{11}$.

Botelho pode ter-se inspirado neste título de Salgado Júnior ou não, dado que a pergunta de Telo é por de mais conhecida. Seja como for, ao alterar o nome da peça que "encenou" para o cinema, quis com certeza interrogar-se, e levar os

10 Daí que o Filme do Desassossego (assim chamou João Botelho ao filme que teve como base o Livro do Desassossego) não tivesse distribuição comercial, mas sessões fora do seu circuito, organizadas para as escolas e associações culturais, e um DVD que foi vendido pelo jornal Correio da Manhã. E o seu sucesso foi muito maior, com sessões esgotadas, como sucedeu no Teatro Gil Vicente, de Coimbra.

11 António Salgado Júnior, Romeiro, romeiro! Quem és tu? (Frei Luís de Sousa, acto II, cena XV): fantasia crítica à maneira de acto dramático, Porto, Maranus, 1956. 
espectadores a interrogar-se, sobre a identidade do sebastianismo, e talvez até sobre a identidade do povo português e dos seu sentimentos psicóticos. "Quem és tu?" - porque será que o povo português tem uma mentalidade doentia, porque será que procura sempre encontrar alguém ou algo que justifique as suas angústias e os seus desaires? Não terá sido essa sensibilidade que terá procurado surpreender na "conversa (in)acabada" de Sá-Carneiro e de Fernando Pessoa, ele próprio que utilizou o sebastianismo como um culto estético? Não terá sido essa mentalidade doentia que procurou analisar em Um Adeus Português ou na psicopatia de Aqui na Terra (1993)?

Será o anti-sebastianismo um dos objectivos de João Botelho, ao voltar a filmar a peça de Garrett, como expressamente o foi em Manuel Alegre, ao escrever o poema "Abaixo El-Rei Sebastião"? Por outras palavras, terá também um sentido de anti-memória? Ou será que pretendeu apenas voltar a analisar esse sentimento peculiar do povo português? Ou tê-lo-á mesmo visto como uma sensibilidade de grande efeito estético?

Neste momento em que a "Europa" foi uma outra "panaceia sebastianista" — que já não é - João Botelho que responda. O certo, certo, é que Botelho, numa atitude de respeito pela memória de Garrett, quis de novo recordá-lo e o seu Frei Luís de Sousa, ao qual, compreensivelmente ou não, deu o título interrogativo de Quem és tu?

* Por vontade do autor, o presente texto não segue as normas do novo Acordo Ortográfico. 